Article

\title{
Cutting Parameter Selection for Efficient and Sustainable Repair of Holes Made in Hybrid Mg-Ti-Mg Component Stacks by Dry Drilling Operations
}

\author{
Eva María Rubio ${ }^{1, *(D)}$, María Villeta ${ }^{2}$, José Luis Valencia ${ }^{2}$ and José Manuel Sáenz de Pipaón ${ }^{1}$ \\ 1 Department of Manufacturing Engineering, Industrial Engineering School, Universidad Nacional de \\ Educación a Distancia (UNED), St/Juan del Rosal 12, E28040 Madrid, Spain; jm@saenzdepipaon.com \\ 2 Department of Statistics and Data Science, Faculty of Statistical Studies, Complutense University of \\ Madrid (UCM), Ave. Puerta de Hierro 1, E28040 Madrid, Spain; mvilleta@estad.ucm.es (M.V.); \\ joseval@estad.ucm.es (J.L.V.) \\ * Correspondence: erubio@ind.uned.es; Tel.: +34-913-988-226
}

Received: 7 July 2018; Accepted: 3 August 2018; Published: 7 August 2018

\begin{abstract}
Drilling is one of the most common machining operations in the aeronautic and aerospace industries. For assembling parts, a large number of holes are usually drilled into the parts so that they can be joined later by rivets. As these holes are subjected to fatigue cycles, they have to be checked regularly for maintenance or repair, since small cracks or damage in its contour can quickly cause breakage of the part, which can have dangerous consequences. This paper focuses on finding the best combinations of cutting parameters to perform repair and maintenance operations of holes in stacked hybrid magnesium-titanium-magnesium components in an efficient, timely, and sustainable (without lubricants or coolants) manner, under dry drilling conditions. For the machining trials, experiments were designed and completed. A product of a full factorial $2^{3}$ and a block of two factors $(3 \times 2)$ was used with surface roughness as the response variable measured as the mean roughness average. Analysis of variance (ANOVA) was used to examine the results. A set of optimized tool and cutting conditions is presented for performing dry drilling repair operations.
\end{abstract}

Keywords: hybrid components stack; titanium; magnesium; repair and maintenance operations; drilling; dry machining; roughness average $(R a)$; ANOVA

\section{Introduction}

Reduction in energy consumption is a constant demand in various industries, such as aeronautic, aerospace, and automotive, due to economic and environmental reasons. However, as energy consumption is closely linked to weight, one method to reduce energy consumption is to use lighter components composed of light alloys, such as titanium (Ti), aluminium (Al), and / or magnesium (Mg), all of which have an excellent weight/mechanical properties ratio.

The parts used in the aforementioned industries have to be rigid, strong, and light. In addition, they have to meet high precision and quality standards. As such, the production of these light alloys has been extensively studied [1-33]. Their repair and maintenance has also been thoroughly studied. Given their uniqueness and high cost, replacement parts are often not available when they have to be maintained or repaired [34-49].

The development of new alloys or polymers that increase the number of applications may be expensive but not always achievable. Sometimes, even when a material exists, it struggles to simultaneously satisfy all the necessary properties for concrete application using the material alone. 
Then, the combination of two or more materials is an alternative for producing hybrid components whose properties satisfy the requirements in areas not covered by the individual components separately [50-58]. Different combinations of materials and technologies have been studied in order to improve their properties [50-70], so the use of hybrid structures is becoming more common.

The complexity of aeronautic and aerospace parts means that most have to be mechanized until achieving their final geometry. Then, using hybrid components, machining together several materials simultaneously is necessary. Drilling is one of the most usual machining operations in these industrial sectors, since it is used to create a large number of holes for assembling the parts. As these holes are subjected to fatigue cycles, every so often they must be checked for their maintenance since small cracks or damage in its contour can quickly degenerate into the breakage of the piece. Given the nature of these environments, breakages can have serious consequences. Due to the cost and complexity of these types of pieces, replacement parts are not maintained in stock to be used for repair or maintenance $[3,36,49]$.

Performing machining operations in complex geometries of hybrid components or stacks is a significant challenge in terms of accuracy and quality, especially when the combined materials are magnesium and titanium. Magnesium is the lighter metal and has good mechanical properties that make magnesium alloys attractive for applications in industries where weight is crucial. Titanium is in demand due to its physical, chemical, and thermal properties. However, both materials present some problems. Magnesium is easily ignited by the heat generated during the machining process. The low thermal conductivity of titanium increases risk of tool wear, its low modulus means that parts move away from the cutting tool during machining, and its high chemical reactivity and low hardness tend to produce cracks in the cutting tools [71-73].

For solving these problems, different compatible and environmentally sustainable lubricants and coolants have been developed $[26,38-40,45,74]$. However, more research is needed because machining hybrid components causes an increase in the instability of the process due to the different cutting characteristics of the different materials. Many investigations have been reported for the simultaneous machining of materials in the search for optimal combinations of cutting conditions, tools, and cooling systems $[56,57,75-89]$.

This paper focuses on drilling processes, and especially on finding the best combinations of cutting conditions and type of tools to perform hole repair and maintenance operations with dry machining on hybrid stacks of $\mathrm{Mg}-\mathrm{Ti}-\mathrm{Mg}$ in the shortest time and most sustainable method possible.

The magnesium-titanium-magnesium stack (Figure 1) was predrilled to simulate repair operations in hybrid components that are assembled with rivets. The two parts of magnesium were considered the base of the stack and the titanium was considered the insert.

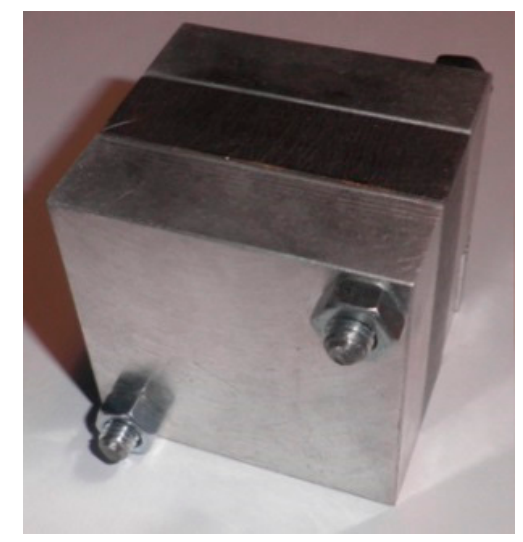

(a)

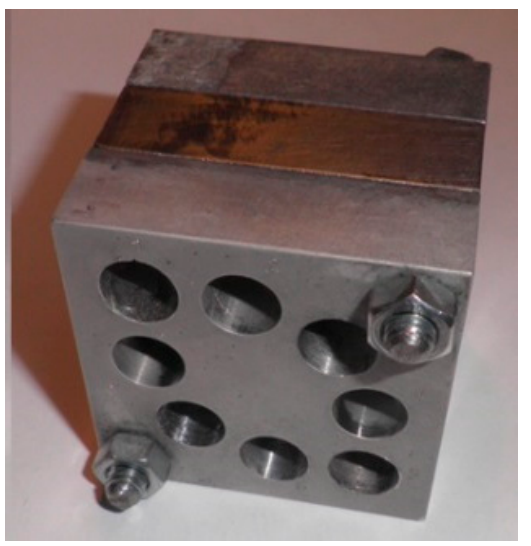

(b)

Figure 1. Hybrid magnesium-titanium-magnesium stack for (a) drilling and (b) hole repair trials [56,57]. 
When a rivet hole is damaged, it has to be drilled to a larger diameter and an oversized rivet has to be assembled. This repair process is widely used in aeronautics and has to be performed with care as cracks in the structure can produce catastrophic consequences.

In this work, the surface roughness on the inside the holes was obtained by drilling the hybrid stacks. The stacks were composed of a magnesium alloy and titanium alloy to determine if it is possible to efficiently and sustainably repair or maintain aeronautic and aerospace industry parts with very strict surface finish requirements. To achieve this goal, a design of experiments (DOE) was defined for the drilling trials and the surface roughness measurements. The design selected was the product of a full factorial $2^{3}$ and a block of two factors $(3 \times 2)$, whose possible influential cutting parameter factors were feed rate, $f$, cutting speed, $V$, and tool coating type, $T$. The location factors in terms of measuring the surface roughness included location on the specimen, $L R S$, and location on the insert, $L R I$. The obtained results were analyzed via analysis of variance (ANOVA), which helped establish a ranking of the parameter combinations based on the surface roughness achieved in the machining trials and helped determine the optimum combination of factors for performing these types of operations.

\section{Materials and Methods}

We followed the guidelines provided by Montgomery [87]. First, in the planning stage, factors, levels, ranges, and response variables were determined (Table 1). Then, the design of experiments (DOE) was performed. The design was elected according to the fixed resources and objectives. In this case, the goal was to analyze the variability in the surface roughness inside the holes obtained by drilling of hybrid stacks composed of UNS M11917 magnesium alloy and UNS R56400 titanium alloy (Table 2). The design selected was the product of a full factorial $2^{3}$ and a block of two factors $(3 \times 2$; $L R I \times L R S)$ with a total of 48 experimental runs, as can be observed in Table 2 . In this table, each line represents two experimental runs, one for each level of the $L R I$ factor.

Next, the machining trials were completed. To execute the drilling trials, it was first necessary to establish the protocols both for the cutting conditions to be used and for registering the obtained data. Then, it was necessary to prepare the workpieces with the specimens of the hybrid stacks, the tools, and the machine tool, introducing the cutting conditions selected. Next, the machining operations were performed, and finally, we photographed and recorded videos of all the trials for further analysis once the process was finished.

Then, we measured the response variable. Surface roughness was selected as the response variable, measured as the roughness average $(R a)$ [88]. Once the data were obtained, we performed a statistical analysis. The variability of the average roughness values, $R a$, was modelled using ANOVA, identifying both the influential factors and interactions among them on surface roughness. In addition, an exploratory data analysis was performed to obtain a clear graphical view of the key aspects in terms of the distribution of the influential factors on the surface finish of hybrid magnesium-titanium-magnesium stacks. The relationships between pairs of influential factors were illustrated and analyzed. After the statistical analysis of the results, some conclusions were established.

Table 1. Factors and levels.

\begin{tabular}{cc}
\hline Factor & Level \\
\hline Feed rate, $f(\mathrm{~mm} / \mathrm{min})$ & $f 1, f 2$ \\
Cutting speed, $V(\mathrm{~m} / \mathrm{min})$ & $V 1, V 2$ \\
Tool coating type, $T$ & $T 1, T 2$ \\
Location with respect to the specimen, $L R S$ & $L R S 1, L R S 2$ \\
Location with respect to the insert, $L R I$ & LRI1, LRI2, LRI3 \\
\hline
\end{tabular}


Table 2. Experimental design: product of a full factorial $2^{3}$ and a block of two factors $3 \times 2$.

\begin{tabular}{|c|c|c|c|c|c|}
\hline$T$ & $V(\mathrm{~m} / \mathrm{min})$ & $f(\mathrm{~mm} / \mathrm{min})$ & $L R I$ & \multicolumn{2}{|c|}{ LRS } \\
\hline T1 & $V 1$ & $f 2$ & LRI2 & LRS1 & LRS2 \\
\hline T1 & $V 1$ & $f 2$ & LRI1 & LRS1 & LRS2 \\
\hline T1 & $V 1$ & $f 2$ & LRI3 & LRS1 & LRS2 \\
\hline T1 & $V 1$ & $f 1$ & LRI3 & LRS1 & LRS2 \\
\hline T1 & $V 1$ & $f 1$ & LRI2 & LRS1 & LRS2 \\
\hline T1 & $V 1$ & $f 1$ & LRI1 & LRS1 & LRS2 \\
\hline T1 & $V 2$ & $f 1$ & LRI2 & LRS1 & LRS2 \\
\hline$T 1$ & $V 2$ & $f 1$ & LRI1 & LRS1 & LRS2 \\
\hline T1 & $V 2$ & $f 1$ & LRI3 & LRS1 & LRS2 \\
\hline$T 2$ & $V 1$ & $f 1$ & LRI3 & LRS1 & LRS2 \\
\hline$T 2$ & $V 1$ & $f 1$ & LRI2 & LRS1 & LRS2 \\
\hline $\mathrm{T} 2$ & $V 1$ & $f 1$ & LRI1 & LRS1 & LRS2 \\
\hline$T 2$ & $V 2$ & $f 2$ & LRI3 & LRS1 & LRS2 \\
\hline$T 2$ & $V 2$ & $f 2$ & LRI2 & LRS1 & LRS2 \\
\hline$T 2$ & $V 2$ & $f 2$ & LRI1 & LRS1 & LRS2 \\
\hline T1 & $V 2$ & $f 2$ & LRI3 & LRS1 & LRS2 \\
\hline T1 & $V 2$ & $f 2$ & LRI1 & LRS1 & LRS2 \\
\hline T1 & $V 2$ & $f 2$ & LRI2 & LRS1 & LRS2 \\
\hline$T 2$ & $V 1$ & $f 2$ & LRI1 & LRS1 & LRS2 \\
\hline$T 2$ & $V 1$ & $f 2$ & LRI2 & LRS1 & LRS2 \\
\hline T2 & $V 1$ & $f 2$ & LRI3 & LRS1 & LRS2 \\
\hline T2 & $V 2$ & $f 1$ & LRI1 & LRS1 & LRS2 \\
\hline T2 & $V 2$ & $f 1$ & LRI2 & LRS1 & LRS2 \\
\hline T2 & $V 2$ & $f 1$ & LRI3 & LRS1 & LRS2 \\
\hline
\end{tabular}

\section{Trials}

This work focused on the manufacturing process of drilling and on repair operations of holes used to join parts of different materials by means of rivets. Materials, cutting tools, cutting conditions, and measurement locations were established as influential factors on the variability in surface roughness.

\subsection{Specimens: Materials and Geometries}

The materials used in the manufacture of the workpieces for hole repair drilling operations included magnesium alloy UNS M11917 and titanium alloy UNS R56400, whose compositions are outlined in Table 3. In the absence of standards, national or international, in relation to the design and manufacture of test pieces, we decided to use $50 \times 50 \times 15 \mathrm{~mm}$ parallelepipeds (Figure 2) [57]. The hybrid component stacks were composed of a total of three pieces or parallelepipeds called specimens: two of magnesium alloy and one of titanium alloy. The two UNS M11917 magnesium alloy specimens were called the base and the UNS R56400 titanium alloy specimen, located between the two magnesium pieces, was called the insert; this is similar to previous works involving other processes and other materials analyzed. The specimens were positioned one above the other to differentiate the measurements when collecting data. The three parallelepipeds or specimens were mechanically fixed together so that it was possible to disassemble and measure the surface roughness inside the machined holes with relative ease. In order to simulate repair and maintenance operations, a test piece was predrilled with a number of holes in accordance with the requirements for the planned experiments. 
Table 3. Chemical compositions of materials used for manufacturing specimens.

\begin{tabular}{cc}
\hline UNS M11917 (AZ91D) & UNS R56400 (Ti-6Al-4V) \\
\hline $\mathrm{Al} 8.30-9.70 \%$ & $\mathrm{Al} 5.5-6.75 \%$ \\
$\mathrm{Cu} \leq 0.03 \%$ & $\mathrm{C} \leq 0.08 \%$ \\
$\mathrm{Fe} \leq 0.005 \%$ & $\mathrm{H} \leq 0.015 \%$ \\
$\mathrm{Mg} 90 \%$ & $\mathrm{Fe} \leq 0.4 \%$ \\
$\mathrm{Mn} \geq 0.13 \%$ & $\mathrm{~N} \leq 0.03 \%$ \\
$\mathrm{Ni} \leq 0.002 \%$ & $\mathrm{O} \leq 0.2 \%$ \\
$\mathrm{Si} \leq 0.1 \%$ & $\mathrm{Ti} 87.725-91 \%$ \\
$\mathrm{Zn} 0.35-1 \%$ & $\mathrm{Zn} 3.5-4.5 \%$ \\
\hline
\end{tabular}

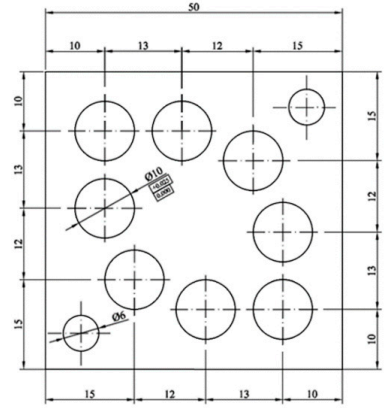

(a)
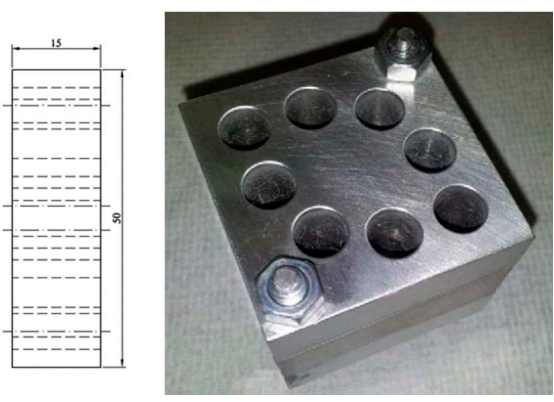

(b)

Figure 2. (a) Design of the geometry of each of the three parts of the workpiece; (b) Predrilled workpiece used during the trials to simulate hole repair operations on hybrid stacks [56,57].

\subsection{Tools}

Two types of tools were selected for drilling operations with the same geometry (Figure 3a) but with different coatings (Figure 3b) (GARANT, Hoffmann Iberia Quality Tools S.L., San Fernando de Henares, Madrid, Spain). We selected tools made of High-Speed Steel (HSS CO): two-flute twist drills with $130^{\circ}$ point angle and in two different qualities, A11240 and A11253. A11240 is recommended for titanium, steel, and stainless steel, whereas A11253 is coated with titanium nitride (TiN) and recommended for steel, stainless steel, titanium, aluminium alloys, and copper alloys. This selection allows us to use the tools in the largest number of trials involving different material combinations, considering that this work is inside a wider project that involves different machining processes (turning, milling, drilling), materials (steel, aluminium, titanium, and magnesium), tools, and workpieces of several types, shapes, and sizes.

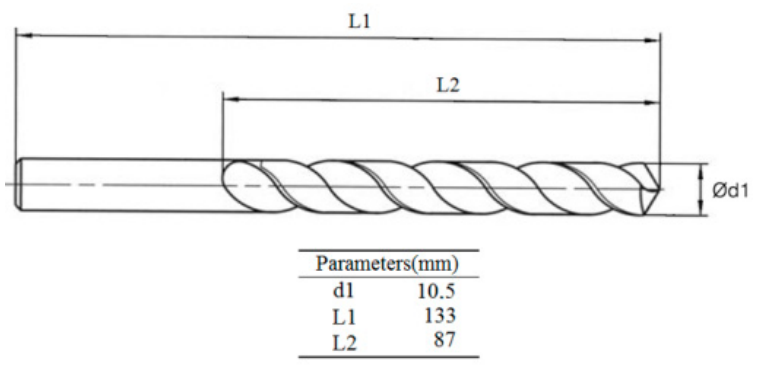

(a)

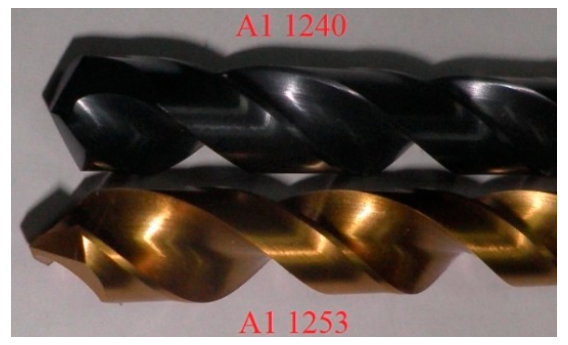

(b)

Figure 3. (a) Drill tool geometry and dimensions; (b) Materials and uses of the tools: A11240 is composed of High-Speed Steel and recommended for titanium, steel, and stainless steel and A11253 is composed of High-Speed Steel coated with titanium nitride and recommended for steel, stainless steel, titanium, aluminium alloys, and copper alloys [64]. 


\subsection{Cutting Parameters}

The trials were carried out in a Tongtai TMV510 machining center (Tongtai Machine \& Tool Co., Luzhu Dist, Kaohsiung City, Taiwan) equipped with a Fanuc Control Numeric Computer (CNC) (FANUC Iberia, Castelldefels, Barcelona, Spain) (Figure 4) under dry conditions. The values usually used during repair and maintenance operations were selected for the factor levels of feed rate, $f: 50 \mathrm{~mm} / \mathrm{min}$ and $100 \mathrm{~mm} / \mathrm{min}$; cutting speed, $V: 20 \mathrm{~m} / \mathrm{min}$ and $25 \mathrm{~m} / \mathrm{min}$; and depth of cut, $d: 0.25 \mathrm{~mm}$.

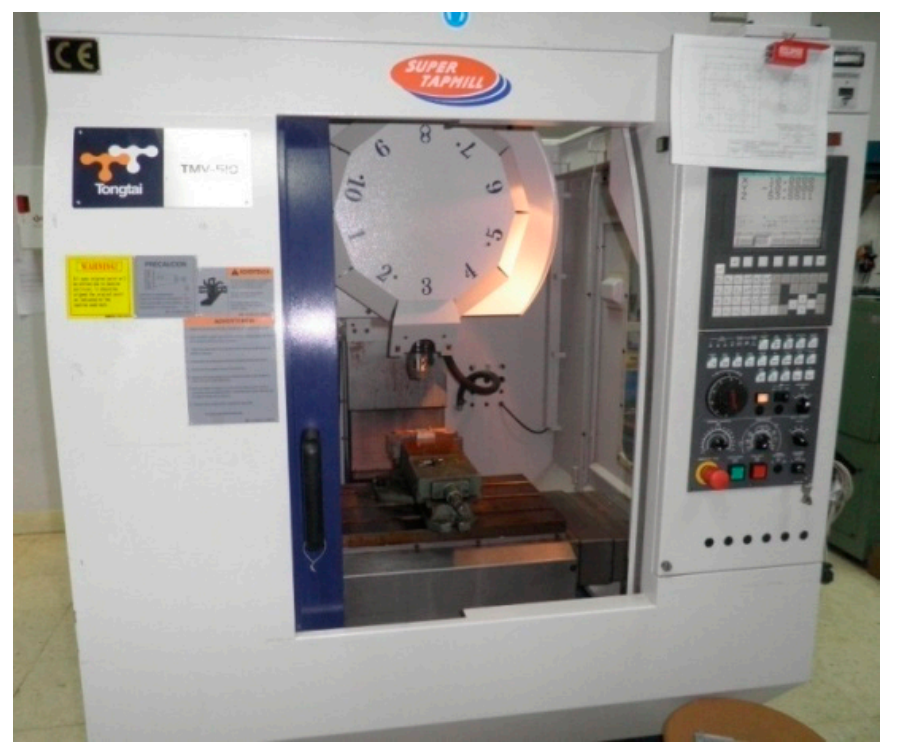

Figure 4. Tongtai TMV510 machining center equipped with a Fanuc Control Numeric Computer (CNC).

\subsection{Measurement Locations}

The measurements of the surface roughness were recorded using a Mitutoyo Surftest SJ 401 roughness tester (Mitutoyo America Corporation, Aurora, IL, USA) (Figure 5a). From Table 1, the measurement locations along with the specimen and the insert were used as influential factors (Figure $5 \mathrm{~b}$ ). These factors are LRS for the specimen and LRI for the insert. For the LRS, two values were chosen: LRS1, the roughness at the beginning of the hole, and LRS2, the roughness at the end of the hole along the feeding direction. Specifically, LRS1 was recorded within the first $7 \mathrm{~mm}$ of the hole and LRS2 was recorded within the last $7 \mathrm{~mm}$ of the hole (Figure $5 \mathrm{c}$ ). For the LRI, three levels were established according to the drilling direction: LRI1, the roughness before the insert (first specimen), which is the roughness inside the holes of the first magnesium piece; LRI2, the roughness on the insert (second specimen), which is the roughness inside the holes of the titanium piece; and LRI3, the roughness after the insert, which is the roughness inside the holes of the second magnesium piece (third specimen). 


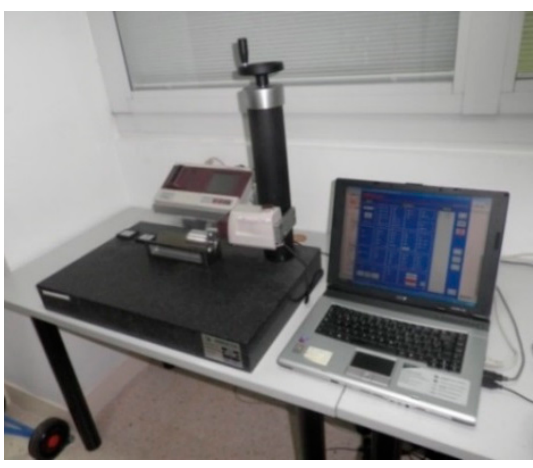

(a)

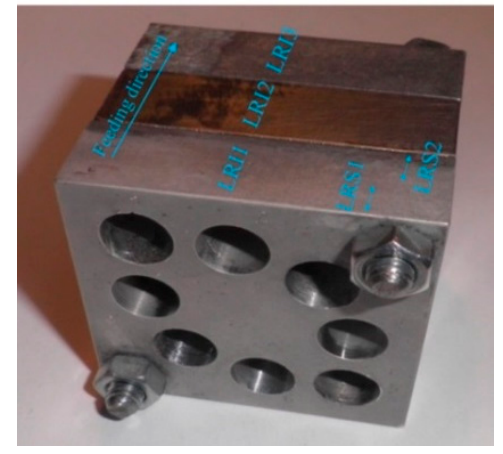

(b)

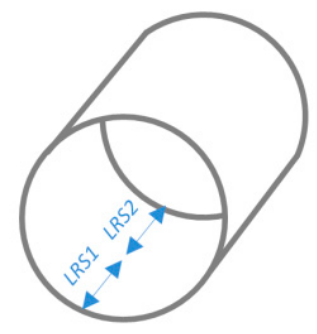

(c)

Figure 5. (a) Mitutoyo Surftest SJ 401 roughness tester; (b) location of the measurements of $L R S$ and $L R I$ along the feeding direction, inside each hole; and (c) detail of the specific measurement locations in the holes of each specimen.

\subsection{Factors and Levels Selected}

The values selected for the levels of factors analyzed in this study are shown in Table 4 . The depth of cut, $d$, was recorded at $25 \mathrm{~mm}$ and was equal in all tests. This value was selected to simulate repair and maintenance operations in which it is necessary to adhere to the tolerance dimensions established during the design of the parts.

Table 4. Factor and level values.

\begin{tabular}{cc}
\hline Factor & Level Value \\
\hline Feed rate, $f,(\mathrm{~mm} / \mathrm{min})$ & $50 / 100$ \\
Cutting speed, $V,(\mathrm{~m} / \mathrm{min})$ & $20 / 25$ \\
Type of tool, $T$ & A1 1253/A1 1240 \\
Location with respect to the specimen, $L R S$ & Beginning of the specimen, end of the specimen \\
Location with respect to the insert, $L R I$ & Before the insert, on the insert, after the insert \\
\hline
\end{tabular}

\section{Results, Analysis, and Discussion}

\subsection{Results}

The surface roughness in terms of the roughness average, $R a$, was measured after performing all the drilling trials inside all the holes and in the different locations established in Table 4, following the direction and locations shown in Figure $5 b, c$ for each hole. The results obtained for the $48 \mathrm{Ra}$ experimental values are outlined in the last two columns of Table 5.

We firstly assessed the initial obtained results to determine any trend and to compare the findings with those obtained in previous works in which the materials were studied separately or along with other materials. The $R a$ mean values in the three measured zones are provided in Table 6 .

The values obtained in this work aligned with those in other previous works about titanium using a similar feed rate, cutting speed, or point angle [81,89-91], as well as with those obtained when drilling magnesium matrix composites [83]. For optimizing magnesium alloys during drilling operations, other point angles are suitable; however, similar surface roughness values were obtained in this work [92]. 
Table 5. Roughness average $R a(\mu \mathrm{m})$ obtained during the experiments.

\begin{tabular}{|c|c|c|c|c|c|}
\hline \multirow{2}{*}{$T$} & \multirow{2}{*}{$V(\mathrm{~m} / \mathrm{mnin})$} & \multirow{2}{*}{$f(\mathrm{~mm} / \mathrm{min})$} & \multirow{2}{*}{$L R I$} & \multicolumn{2}{|c|}{$R a(\mu \mathrm{m})$} \\
\hline & & & & LRS1 & LRS2 \\
\hline A11253 & 20 & 100 & LRI2 & 1.28 & 3.09 \\
\hline A11253 & 20 & 100 & LRI1 & 0.36 & 1.73 \\
\hline A11253 & 20 & 100 & LRI3 & 1.52 & 2.28 \\
\hline A11253 & 20 & 50 & LRI3 & 1.91 & 6.28 \\
\hline A11253 & 20 & 50 & LRI2 & 0.74 & 1.46 \\
\hline A11253 & 20 & 50 & LRI1 & 1.23 & 0.31 \\
\hline A11253 & 25 & 50 & LRI2 & 0.86 & 0.89 \\
\hline A11253 & 25 & 50 & LRI1 & 0.10 & 0.87 \\
\hline A11253 & 25 & 50 & LRI3 & 0.78 & 1.09 \\
\hline A11240 & 20 & 50 & LRI3 & 0.64 & 1.94 \\
\hline A11240 & 20 & 50 & LRI2 & 0.86 & 1.13 \\
\hline A11240 & 20 & 50 & LRI1 & 1.73 & 1.54 \\
\hline A11240 & 25 & 100 & LRI3 & 0.83 & 1.43 \\
\hline A11240 & 25 & 100 & LRI2 & 0.80 & 0.85 \\
\hline A11240 & 25 & 100 & LRI1 & 1.59 & 0.77 \\
\hline A11253 & 25 & 100 & $L R I 3$ & 1.81 & 1.79 \\
\hline A11253 & 25 & 100 & LRI1 & 1.73 & 0.37 \\
\hline A11253 & 25 & 100 & LRI2 & 1.60 & 1.03 \\
\hline A11240 & 20 & 100 & LRI1 & 0.68 & 0.45 \\
\hline A11240 & 20 & 100 & LRI2 & 1.11 & 0.87 \\
\hline A11240 & 20 & 100 & LRI3 & 0.61 & 1.28 \\
\hline A11240 & 25 & 50 & LRI1 & 2.62 & 1.65 \\
\hline A11240 & 25 & 50 & $L R I 2$ & 1.19 & 1.34 \\
\hline A11240 & 25 & 50 & LRI3 & 1.63 & 1.78 \\
\hline
\end{tabular}

Table 6. $R a(\mu \mathrm{m})$ mean values in the three measured zones versus the feed rate, $f$, and the cutting speed, $V$.

\begin{tabular}{lcccc}
\hline \multirow{2}{*}{$\boldsymbol{a}(\boldsymbol{\mu \mathbf { m }})$} & \multicolumn{2}{c}{$\boldsymbol{f}(\mathbf{m m} / \mathbf{m i n})$} & \multicolumn{2}{c}{$\boldsymbol{V}(\mathbf{m} / \mathbf{m i n})$} \\
\cline { 2 - 5 } & $\mathbf{5 0}$ & $\mathbf{1 0 0}$ & $\mathbf{2 0}$ & $\mathbf{2 5}$ \\
\hline$R a_{\text {LRI }}$ & 1.26 & 0.96 & 1.00 & 1.21 \\
$R a_{\text {LRI2 }}$ & 1.06 & 1.33 & 1.32 & 1.08 \\
$R a_{\text {LRI3 }}$ & 2.01 & 1.44 & 2.06 & 1.39 \\
\hline
\end{tabular}

\subsection{Analysis and Discussion}

In order to statistically analyze the experimental $R a$ data collected (Table 5), a fixed effects ANOVA was performed to examine the interactions up to second order and excluding an effect each time. The selection criteria of the significant effects in the ANOVA after each iteration were as follows [93]: in each new ANOVA, the effect with a higher $p$-value (which was therefore less statistically significant) was excluded; the backward algorithm finishes when all the effects that remain in the ANOVA have a $p$-value lower than 0.05 .

The final outcome of this iterative ANOVA algorithm over the experimental $R a$ data did not lead to any conclusive result. For that reason, a logarithmic transformation of the experimental $R a$ data was performed. Such a transformation allows maintaining the order of the original $R a$ data while smoothing the impact of the outliers. The outcome of the first iteration of the ANOVA over the transformed $R a$ data-over the $R a$ Naperian logarithm $\ln R a$-is provided in Table 7 . A second iteration for the ANOVA was then completed for the effects contained in the table, excluding the $L R I^{*} V$ effect which had a maximum $p$-value of 0.828 . 
Table 7. Outcome of the first iteration for the ANOVA over Ra Naperian logarithm.

\begin{tabular}{cccccc}
\hline Effect & DF & Sum of Squares & Mean Square & $\boldsymbol{F}$-Value & Pr $>\boldsymbol{F}$ \\
\hline$L R I$ & 2 & 2.426 & 1.213 & 3.77 & 0.036 \\
$T$ & 1 & 0.007 & 0.007 & 0.02 & 0.823 \\
$T^{*} L R I$ & 2 & 3.041 & 1.521 & 4.73 & 0.017 \\
$f$ & 1 & 0.021 & 0.021 & 0.06 & 0.802 \\
$L R I^{*} f$ & 2 & 0.225 & 0.112 & 0.35 & 0.708 \\
$T^{*} f$ & 1 & 2.206 & 2.206 & 6.86 & 0.014 \\
$L R S$ & 1 & 0.492 & 0.492 & 1.53 & 0.227 \\
$L R I^{*} L R S$ & 2 & 0.886 & 0.443 & 1.38 & 0.270 \\
$T^{*} L R S$ & 1 & 0.177 & 0.177 & 0.55 & 0.465 \\
$f^{*} L R S$ & 1 & 0.214 & 0.214 & 0.67 & 0.422 \\
$V$ & 1 & 0.092 & 0.092 & 0.29 & 0.597 \\
$L R I^{*} V$ & 2 & 0.122 & 0.061 & 0.19 & 0.828 \\
$T^{*} V$ & 1 & 1.565 & 1.565 & 4.86 & 0.036 \\
$f^{*} V$ & 1 & 0.211 & 0.211 & 0.65 & 0.425 \\
$V^{*} L R S$ & 1 & 0.429 & 0.429 & 1.33 & 0.259 \\
Error & 27 & 8.686 & 0.322 & & \\
Total & 47 & 20.800 & & & \\
\hline
\end{tabular}

DF: Degrees of Freedom.

The final result of the backward algorithm for the last iteration is displayed in Table 8. In this table, all the $p$-values are lower than 0.05 , so the three effects in the first column of this table can be considered statistically significant. Therefore, as a consequence of the ANOVA, we concluded that the interaction between type of tool and the location with respect to the insert $T^{*} L R I$, the location with respect to the insert $L R I$, and the interaction between type of tool and feed rate $T^{*} f$ are the three effects among the 15 analyzed with a significant statistical influence on the surface finish of the machining on the dry drilling stack, composed of magnesium alloy UNS M11917 and titanium alloy UNS R56400. For example, the LRS effect, which measures the roughness differences between the beginning and end of the specimen along the feeding direction, did not have a statistically significant influence on the surface finish because this effect was not included in the outcome of the last iteration for the ANOVA summarized in Table 8.

Table 8. Outcome of the last iteration for the ANOVA over Ra Naperian logarithm.

\begin{tabular}{cccccc}
\hline Effect & DF & Sum of Squares & Mean Square & $\boldsymbol{F}$-Value & $\operatorname{Pr}>\boldsymbol{F}$ \\
\hline$T^{*} f$ & 1 & 2.206 & 2.206 & 7.06 & 0.011 \\
$L R I$ & 2 & 2.426 & 1.213 & 3.88 & 0.028 \\
$T^{*} L R I$ & 2 & 3.041 & 1.521 & 4.87 & 0.013 \\
Error & 42 & 13.127 & 0.313 & & \\
Total & 47 & 20.800 & & & \\
\hline
\end{tabular}

DF: Degrees of Freedom.

Considering the variability in the surface roughness of the magnesium-titanium-magnesium drilling stacks explained by the statistically significant effects obtained from the ANOVA, the percentage of variability attributed to each effect is shown in the pictogram in Figure 6 . The contribution of each effect was obtained as the ratio of the sum of squares of the effect to the sum of squares due to the model. For example, the percentage of variability attributed to the $T^{*} f$ effect is the ratio of 2.206 to $7.673(\%)$. That is, $39.63 \%$ of the variability is due to the $T^{*} L R I$ effect, $31.63 \%$ of the variability is due to the $L R I$ effect, and the remaining $28.73 \%$ of the variability is due to the $T^{*} f$ effect. 


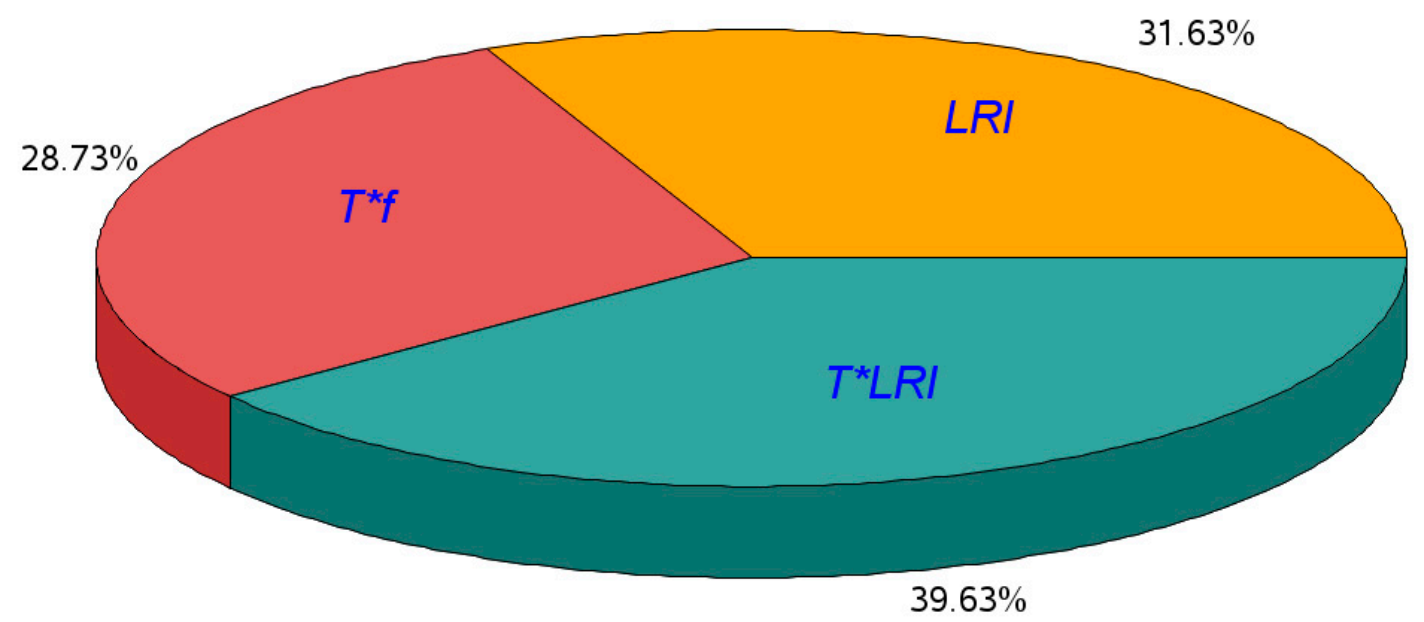

Figure 6. Distribution of the percentage of variability attributed to each effect over the variability explained by the ANOVA model.

The distribution of the Naperian logarithm of the surface roughness of the drilling process $(\ln R a)$ with respect to the three levels of the measurement location on the insert (LRI) is depicted in Figure 7. As shown in the figure, small differences existed between $\ln R a$ before and after the insert. The dispersion is observably greater for small values before the insert.

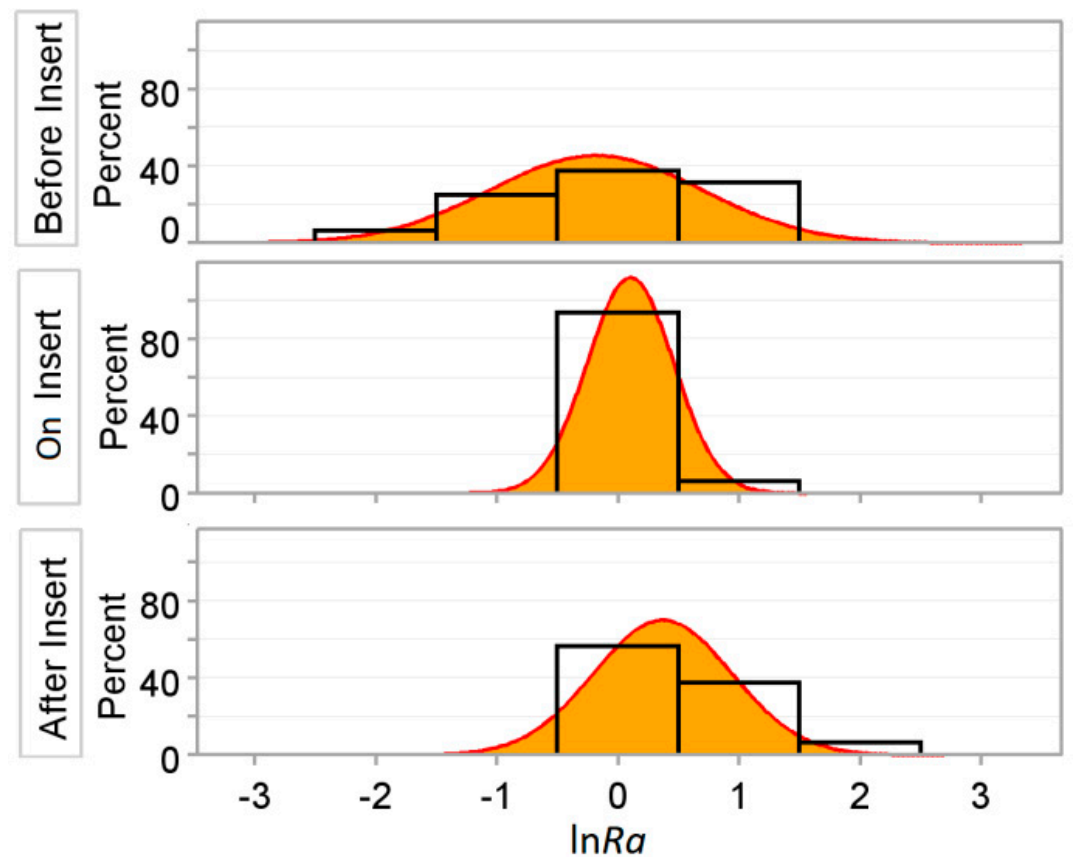

Figure 7. Distribution of the Naperian logarithm of the surface roughness $(\ln R a)$ for each of the three levels of measurement location on the insert $(L R I)$.

On the other hand, when assessing statistically significant interactions, considering the behavior of the interaction between type of tool and the location with respect to the insert $T^{*} L R I$, the A1 1253 tool produced better results in terms of roughness before the insert and worse after the insert. This did not occur with the A1 1240 tool, which had a few differences. This behavior is illustrated in Figure 8 . 


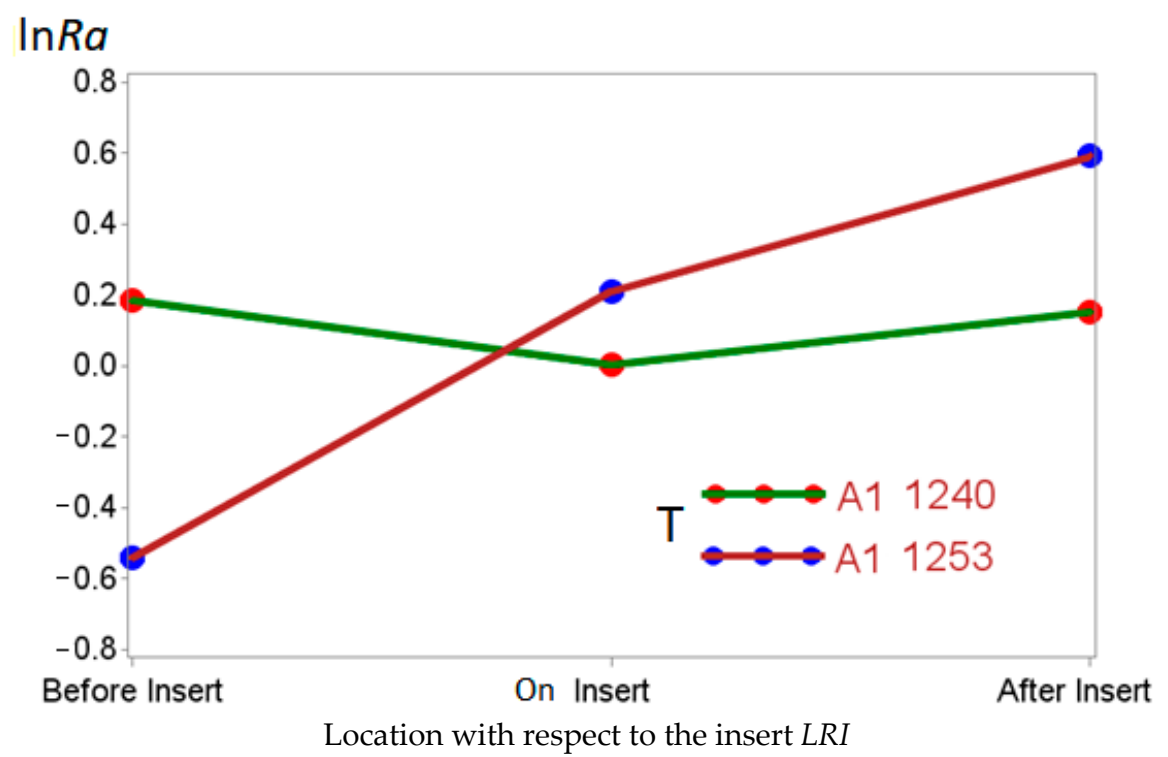

Figure 8. $\ln R a$ interaction between type of tool and the location with respect to the insert $T^{*} L R I$.

With respect to the interaction between type of tool and feed rate $T^{*} f$ (Figure 9), an increase in the advance of $f$ generated a reduction in the roughness for the A1 1240 tool, whereas for the A1 1253 tool, the opposite occurred. The figure clearly demonstrates the $T^{*} f$ interaction.

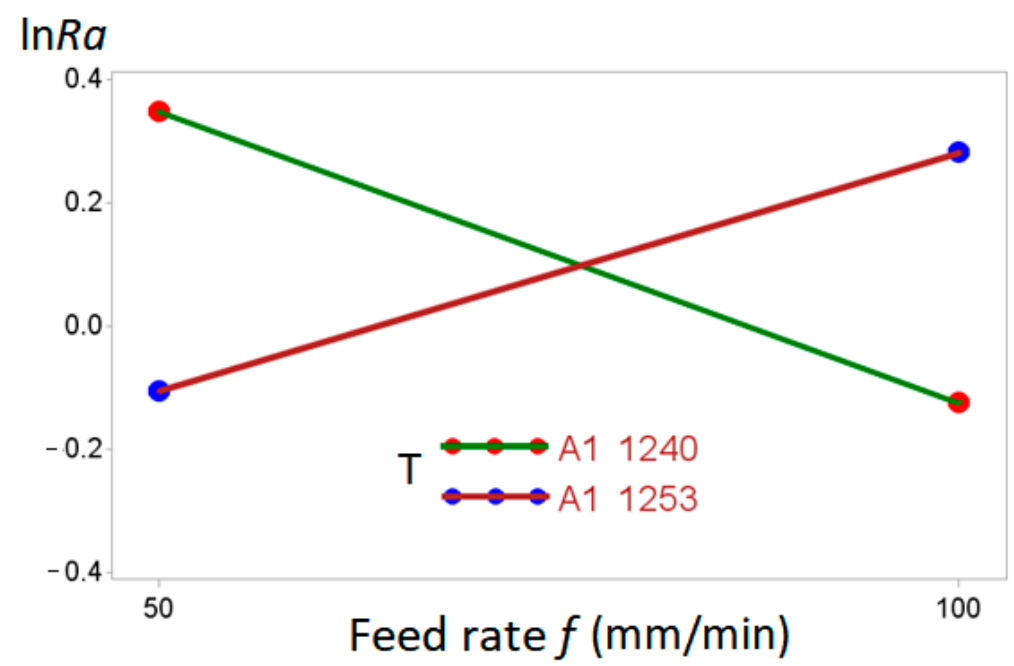

Figure 9. $\ln R a$ interaction between type of tool and feed rate $T^{*} f$.

The variability in the logarithm of the surface roughness $\ln R a$ of dry drilling magnesium-titaniummagnesium stacks was modelled from the ANOVA using Equation (1). In this equation, $\mu$ is a constant term to adjust the mean; $\alpha_{i}, \beta \alpha_{j i}$ and $\beta \gamma_{j k}$ represent the effects of the levels of the location with respect to the insert, the interaction of the type of tool with the measurement location with respect to the insert, and the interaction of the type of tool with the feed rate, respectively; and $\varepsilon_{i j k}$ is the error term.

$$
\ln R a_{i j k}=\mu+\alpha_{i}+\beta \alpha_{j i}+\beta \gamma_{j k}+\varepsilon_{i j k}
$$

The estimations of the parameters of the model in Equation (1) are listed in the third column of Table 9. The table also includes an indicator of the parameter estimation errors (the standard deviation) 
in the fourth column. The fifth column collects the $t$-statistic values, and the sixth column provides the statistical significances of the parameter estimations.

Table 9. Parameter estimations of the model in Equation (1).

\begin{tabular}{cccccc}
\hline Parameter & Designation & Estimation & Standard Error & $\boldsymbol{t}$-Value & $\operatorname{Pr}>|t|$ \\
\hline Intercept & $\mu$ & 0.7862 & 0.2336 & 3.37 & 0.0017 \\
A1 $1253^{*} 50(\mathrm{~mm} / \mathrm{min})$ & $\beta \gamma_{11}$ & -0.3873 & 0.2336 & -1.66 & 0.1052 \\
A1 $1253^{*} 100(\mathrm{~mm} / \mathrm{min})$ & $\beta \gamma_{12}$ & 0 &. &. &. \\
A1 $1240^{*} 50(\mathrm{~mm} / \mathrm{min})$ & $\beta \gamma_{21}$ & -0.4004 & 0.3304 & -1.21 & 0.2326 \\
A1 $1240^{*} 100(\mathrm{~mm} / \mathrm{min})$ & $\beta \gamma_{22}$ & -0.8706 & 0.3304 & -2.64 & 0.0119 \\
Before the insert & $\alpha_{1}$ & -1.1333 & 0.2861 & -3.96 & 0.0003 \\
On the insert & $\alpha_{2}$ & -0.3820 & 0.2861 & -1.34 & 0.1894 \\
After the insert & $\alpha_{3}$ & 0 &. &. &. \\
A1 1253*Before the insert & $\beta \alpha_{11}$ & 0 &. &. &. \\
A1 1253*On the insert & $\beta \alpha_{12}$ & 0 &. &. &. \\
A1 1253*After the insert & $\beta \alpha_{13}$ & 0 &. &. &. \\
A1 1240*Before the insert & $\beta \alpha_{21}$ & 1.1654 & 0.4046 & 2.88 & 0.0064 \\
A1 1240*On the insert & $\beta \alpha_{22}$ & 0.2335 & 0.4046 & 0.58 & 0.5671 \\
A1 1240*After the insert & $\beta \alpha_{23}$ & 0 &. &. &. \\
\hline
\end{tabular}

The parameter estimations included in Table 9 allowed us to obtain the residuals of the model in Equation (2), which provides the differences between the observed values and the estimated values of $\ln R a$. Analyzing these residuals, the model hypotheses were checked. Figure 10 shows that the residuals follow a normal law, so the hypothesis is supported. This hypothesis can be contrasted by different tests, such as normality on residuals, as shown in Table 10.

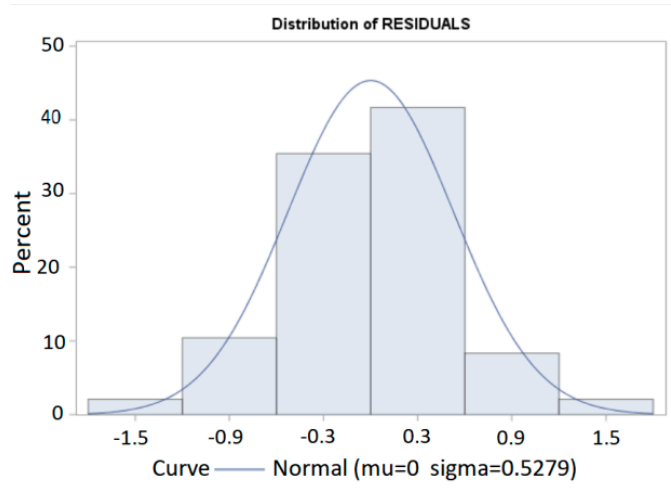

(a)

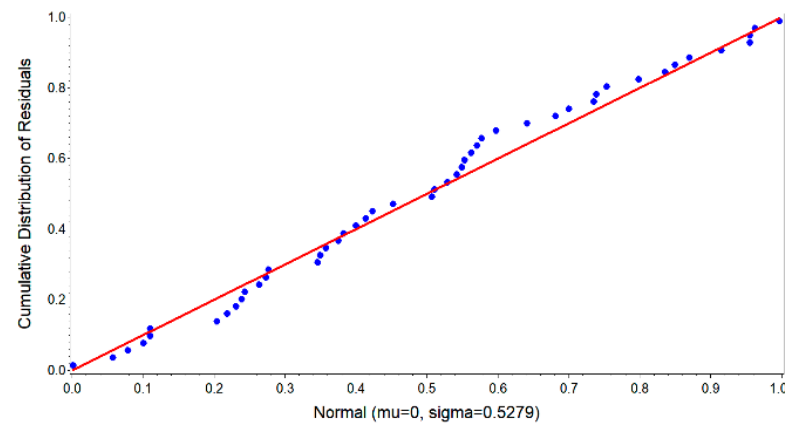

(b)

Figure 10. Checking the hypothesis of normality for the residuals: (a) histogram of residuals and (b) Probability-Probability plot for residuals.

Table 10. Tests for normality on residuals.

\begin{tabular}{ccccc}
\hline Test for Normality & \multicolumn{2}{c}{ Statistic } & \multicolumn{2}{c}{$p$-Value } \\
\hline Shapiro-Wilk & W & 0.977919 & $\operatorname{Pr}<W$ & 0.4952 \\
Kolmogorov-Smirnov & D & 0.0900 & $\operatorname{Pr}>$ D & $>0.150$ \\
\hline
\end{tabular}

Figure 11a shows that the residuals satisfy the homoscedasticity hypothesis and Figure 11b shows that the existence of nonrandomized patterns in the residuals was not observed. 


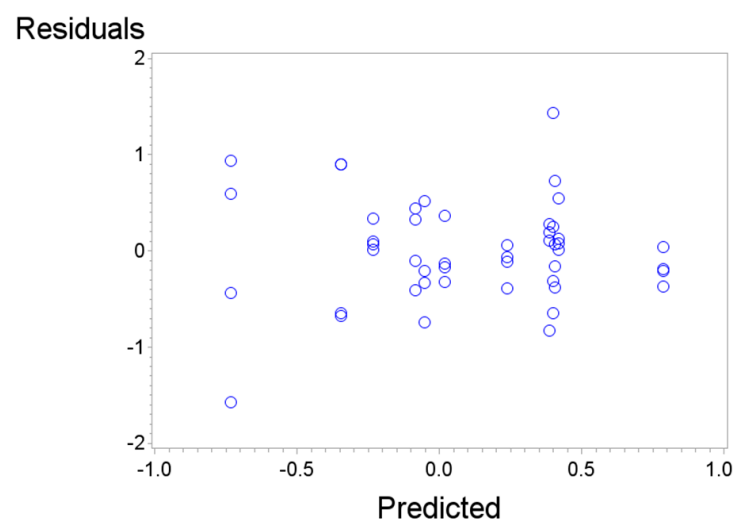

(a)

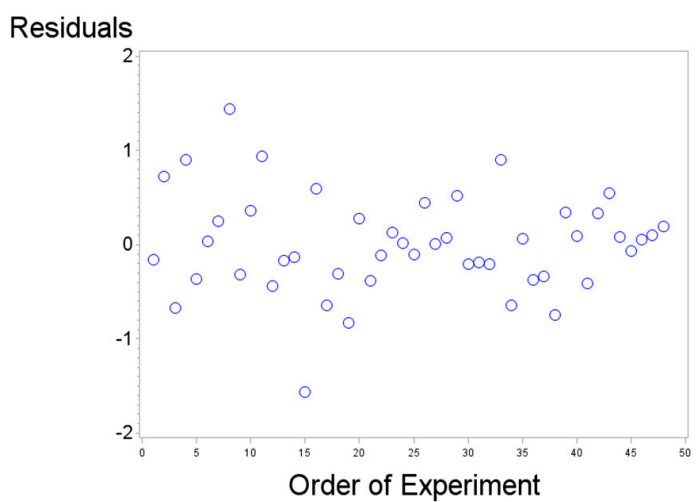

(b)

Figure 11. (a) Checking the homoscedasticity hypothesis for residuals; (b) Checking the nonexistence of special patterns on residuals.

Once the hypotheses of the model in Equation (1) were checked, we confirmed that the variability in the surface roughness $R a$ of dry drilling stacks composed of magnesium alloy UNS M11917 and titanium alloy UNS R56400 could be statistically modelled by Equation (2).

$$
R a_{i j k}=\exp \left(\mu+\alpha_{i}+\beta \alpha_{j i}+\beta \gamma_{j k}+\varepsilon_{i j k}\right)
$$

From modelling the surface roughness Ra described in Equation (2), and considering the parameter estimations in Table 9, the predicted values for surface roughness of the drilling machining were computed for the various combinations of the levels of the statistically significant effects in the surface finish of the dry drilling stacks. The values of the predicted roughness of these combinations are listed in increasing order in Table 11. The second predicted roughness, denoted with an asterisk $\left(^{*}\right)$ and included in the last column of the table, contains the predicted $R a$ values using only the parameters with a statistical significance at the $p<0.05$ level. Considering this second roughness prediction $\left(^{*}\right)$, the combinations of the levels of statistically significant effects were classified into four roughness classes, as shown in the last column of Table 11.

Table 11. Predicted roughness of the level combinations of significant effects on dry drilling.

\begin{tabular}{|c|c|c|c|c|c|}
\hline$L R I$ & $T$ & $f(\mathrm{~mm} / \mathrm{min})$ & $\begin{array}{l}\ln R a \text { Predicted } \\
\alpha_{i}+\beta \alpha_{j i}+\beta \gamma_{j k}\end{array}$ & $\begin{array}{c}R a \text { Predicted }(\mu \mathrm{m}) \\
\exp \left(\alpha_{i}+\beta \alpha_{j i}+\beta \gamma_{j k}\right)\end{array}$ & $\begin{array}{c}R a \text { Predicted }{ }^{*}(\mu \mathrm{m}) \\
\exp \left(\alpha_{i}{ }^{*}+\beta \alpha_{j i}{ }^{*}+\beta \gamma_{j k}{ }^{*}\right)\end{array}$ \\
\hline Before insert & A1 1253 & 50 & -0.734 & 0.48 & \multirow{2}{*}{0.71 (Class I) } \\
\hline Before insert & A1 1253 & 100 & -0.347 & 0.71 & \\
\hline On insert & A1 1240 & 100 & -0.233 & 0.79 & \multirow{2}{*}{0.92 (Class II) } \\
\hline After insert & A1 1240 & 100 & -0.084 & 0.92 & \\
\hline Before insert & A1 1240 & 100 & -0.052 & 0.95 & 0.95 (Class III) \\
\hline On insert & A1 1253 & 50 & 0.017 & 1.02 & \multirow{7}{*}{2.20 (Class IV) } \\
\hline On insert & A1 1240 & 50 & 0.237 & 1.27 & \\
\hline After insert & A1 1240 & 50 & 0.386 & 1.47 & \\
\hline After insert & A1 1253 & 50 & 0.399 & 1.49 & \\
\hline On insert & A1 1253 & 100 & 0.404 & 1.50 & \\
\hline Before insert & A1 1240 & 50 & 0.418 & 1.52 & \\
\hline After insert & A1 1253 & 100 & 0.786 & 2.20 & \\
\hline
\end{tabular}

Focusing on this classification, the best combinations of the levels of parameters that achieved a lower predicted roughness value (a better surface finish) during the dry drilling process on a stack composed of magnesium alloy UNS M11917 and titanium alloy UNS R56400 included the A1 1240 cutting tool with a feed rate of $100 \mathrm{~mm} / \mathrm{min}$. Appropriate levels of surface finish should be 
achieved by these drilling conditions: a predicted roughness of $0.92 \mu \mathrm{m}$ on the insert and after the insert (in the second class), and a predicted roughness of $0.95 \mu \mathrm{m}$ before the insert (in the third class). A mean roughness $R a$ under $1 \mu \mathrm{m}$ could be achieved in all the stack superficial areas.

These types of light alloys are usually employed in the aeronautical industry and in this industrial sector, the values for the surface roughness specifications of $R a$ usually lie between $0.8 \mu \mathrm{m}$ and $1.6 \mu \mathrm{m}$ [91]. As such, roughness values $R a$ under $1 \mu \mathrm{m}$ clearly satisfy the surface finish requirements. Notably, the quality improvement in the surface finish was achieved with higher feed rates, which promoted a decrease in machining time and, consequently, a decrease in costs, enabling the efficient optimization of the surface quality.

\subsection{Technological Point of View}

To apply the results obtained in this study, analyzing them from a technological point of view was necessary. Thus, as most components in the aeronautical and aerospace sectors are complex and have strict dimensional and surface quality requirements (within the range of $0.8 \mu<R a<1.6 \mu \mathrm{m}$ [94]), their manufacturing is usually expensive and pieces are not stocked for repair or maintenance purposes. Therefore, parts have to be repaired or maintained as soon as possible to restore the plane or the aircraft to its functional conditions.

In this study, the best results were obtained for the following combinations of cutting parameters: $f=100 \mathrm{~mm} / \mathrm{min}, V=25$, and $T=\mathrm{A} 11240 \mathrm{~m} / \mathrm{min}$; and $f=50 \mathrm{~mm} / \mathrm{min}, V=25$, and $T=\mathrm{A} 11253 \mathrm{~m} / \mathrm{min}$. The surface roughness achieved in the holes of the different materials and locations in the stack were all within the range usually required in the aeronautical industry [94]. Between the two combinations, the first was better due to the feed rate value being higher so the repair operation can be finished in a shorter time, thereby reducing costs associated with the operation. Additionally, these real results are in accordance with the results of the ranking of the cutting condition combinations based on the estimated values of $R a$.

Performing all tests under dry conditions is important not only from an economic point of view but an environmental viewpoint as well. Not using any additional lubricant or coolant provides cost savings and allows for more sustainable repair and maintenance operations.

\section{Conclusions}

In this paper, we examined a drilling process on a stack formed by two UNS M11917 magnesium alloy bases and one UNS R56400 titanium alloy insert in an experimental study. The interaction between the type of tool and the measurement location on the insert influences the inner surface of the holes. The best type of tool for the drilling repair operations was determined to be the A1 1240, which was especially efficient for higher values of feed rate $(100 \mathrm{~mm} / \mathrm{min})$ and cutting speed $(25 \mathrm{~m} / \mathrm{min})$. The surface roughness obtained in the inner of the holes was independent of material and location considered, and the values fell within the usual acceptable range in the aeronautical sector. The surface roughness increased as the tool advanced through the stack, especially after the insert. However, the differences observed along each component in the stack, at both the beginning and the end of the component, were not statistically significant. The repair operations performed with drilling can be sustainably completed, as was proven in this study, which was completed under dry conditions.

Author Contributions: Conceptualization, E.M.R., M.V., J.L.V. and J.M.S.d.P.; Data curation, E.M.R. and J.M.S.d.P.; Formal analysis, E.M.R., M.V., J.L.V. and J.M.S.d.P.; Funding acquisition, E.M.R., M.V. and J.L.V.; Investigation, E.M.R., M.V., J.L.V. and J.M.S.d.P.; Methodology, E.M.R., M.V. and J.L.V.; Project administration, E.M.R.; Resources, E.M.R.; Software, M.V. and J.L.V.; Supervision, E.M.R., M.V. and J.L.V.; Validation, E.M.R., M.V., J.L.V. and J.M.S.d.P.; Visualization, E.M.R., M.V., J.L.V. and J.M.S.d.P.; Writing-original draft, E.M.R., M.V., J.L.V. and J.M.S.d.P.; Writing-review \& editing, E.M.R., M.V., J.L.V. and J.M.S.d.P.

Funding: This work has been funding, in part, by five grants from Ministerio de Ciencia e Innovación, Ministerio de Economía y Competitividad, AgenciaEstatal de Investigación (AEI), Fondo Europeo de Desarrollo Regional (FEDER), and Industrial Engineering School-UNED (DPI2014-58007-R, CGL2014-58322-R MTM2016-78227-C2-1-P, MTM2017-90584-REDT and REF2018-ICF05), Spain. 
Acknowledgments: The authors thank the Research Group of the UNED "Industrial Production and Manufacturing Engineering (IPME)" for the support given during the development of this work and they also thank the Antolín Group for the material provided.

Conflicts of Interest: The authors declare no conflict of interest.

\section{References}

1. Pervaiz, S.; Deiab, I.; Darras, B. Power consumption and tool wear assessment when machining titanium alloys. Int. J. Precis. Eng. Manuf. 2013, 14, 925-936. [CrossRef]

2. Calamaz, M.; Dominique, C.; Franck, G. A new material model for 2D numerical simulation of serrated chip formation when machining titanium alloy Ti-6Al-4V. Int. J. Mach. Tools Manuf. 2008, 48, 275-288. [CrossRef]

3. Khanna, N.; Davim, J.P. Design-of-Experiments application in machining titanium alloys for aerospace structural components. Measurement 2015, 61, 280-290. [CrossRef]

4. Wyen, C.F.; Wegener, K. Influence of cutting edge radius on cutting forces in machining titanium. CIRP Ann. 2010, 59, 93-96. [CrossRef]

5. Kuttolamadom, M.; Joshua, J.; Laine, M.; Von Oehsen, J.; Kurfess, T.; Ziegert, J. High performance computing simulations to identify process parameter designs for profitable titanium machining. J. Manuf. Syst. 2017, 43, 235-247. [CrossRef]

6. Jackson, M.J.; Novakov, T.; Whitfield, M.; Robinson, G.; Handy, R.; Sein, H.; Ahmed, W. VFCVD Diamond-Coated cutting tools for micro-machining titanium alloy Ti6Al4V. Int. J. Adv. Manuf. Technol. 2017, 92, 2881-2918. [CrossRef]

7. Pervaiz, S.; Amir, R.; Ibrahim, D.; Cornel, M.N. An experimental investigation on effect of minimum quantity cooling lubrication (MQCL) in machining titanium alloy (Ti6Al4V). Int. J. Adv. Manuf. Technol. 2016, 87, 1371-1386. [CrossRef]

8. Yang, X.P.; Liu, C.R. Machining titanium and its alloys. Mach. Sci. Technol. 1999, 3, 107-139. [CrossRef]

9. Hoyne, A.C.; Nath, C.; Kapoor, S.G. On cutting temperature measurement during titanium machining with an atomization-based cutting fluid spray system. J. Manuf. Sci. Eng. 2015, 137, 024502. [CrossRef]

10. Liu, Z.Q.; Xu, J.Y.; Han, S.; Chen, M. A coupling method of response surfaces (CRSM) for cutting parameters optimization in machining titanium alloy under minimum quantity lubrication (MQL) condition. Int. J. Precis. Eng. Manuf. 2013, 14, 693-702. [CrossRef]

11. Ramesh, S.; Karunamoorthy, L.; Palanikumar, K. Fuzzy modeling and analysis of machining parameters in machining titanium alloy. Mater. Manuf. Process. 2008, 23, 439-447. [CrossRef]

12. Revuru, R.S.; Zhang, J.Z.; Posinasetti, N.R.; Kidd, T. Optimization of titanium alloys turning operation in varied cutting fluid conditions with multiple machining performance characteristics. Int. J. Adv. Manuf. Technol. 2018, 95, 1451-1463. [CrossRef]

13. Sun, J.; Guo, Y.B. Material flow stress and failure in multiscale machining titanium alloy Ti-6Al-4V. Int. J. Adv. Manuf. Technol. 2009, 41, 651-659. [CrossRef]

14. Sun, S.; Brandt, M.; Dargusch, M.S. Characteristics of cutting forces and chip formation in machining of titanium alloys. Int. J. Mach. Tools Manuf. 2009, 49, 561-568. [CrossRef]

15. Sima, M.; Tuğrul, Ö. Modified material constitutive models for serrated chip formation simulations and experimental validation in machining of titanium alloy Ti-6Al-4V. Int. J. Mach. Tools Manuf. 2010, 50, 943-960. [CrossRef]

16. Liu, Z.; Qinglong, A.; Jinyang, X.; Ming, C.; Shu, H. Wear performance of (Nc-AlTiN)/(a-Si $\left.{ }_{3} \mathrm{~N}_{4}\right)$ coating and $(\mathrm{Nc}-\mathrm{AlCrN}) /\left(\mathrm{a}-\mathrm{Si}_{3} \mathrm{~N}_{4}\right)$ coating in high-speed machining of titanium alloys under dry and minimum quantity lubrication (MQL) conditions. Wear 2013, 305, 249-259. [CrossRef]

17. Kannan, S.; Kishawy, H.A. Tribological aspects of machining aluminium metal matrix composites. J. Mater. Process. Technol. 2008, 198, 399-406. [CrossRef]

18. Sreejith, P.S. Machining of 6061 aluminium alloy with MQL, dry and flooded lubricant conditions. Mater. Lett. 2008, 62, 276-278. [CrossRef]

19. Nouari, M.; List, G.; Girot, F.; Coupard, D. Experimental analysis and optimisation of tool wear in dry machining of aluminium alloys. Wear 2003, 255, 1359-1368. [CrossRef]

20. Kelly, J.F.; Cotterell, M.G. Minimal lubrication machining of aluminium alloys. J. Mater. Process. Technol. 2002, 120, 327-334. [CrossRef] 
21. Davoodi, B.; Tazehkandi, A.H. Experimental investigation and optimization of cutting parameters in dry and wet machining of aluminum alloy 5083 in order to remove cutting fluid. J. Clean. Prod. 2014, 68, 234-242. [CrossRef]

22. Kouadri, S.; Necib, K.; Atlati, S.; Haddag, B.; Nouari, M. Quantification of the chip segmentation in metal machining: Application to machining the aeronautical aluminium alloy AA2024-T351 with cemented carbide tools WC-Co. Int. J. Mach. Tools Manuf. 2013, 64, 102-113. [CrossRef]

23. Hovsepian, P.E.; Luo, Q.; Robinson, G.; Pittman, M.; Howarth, M.; Doerwald, D.; Tietema, R.; Sim, W.M.; Deeming, A.; Zeus, T. TiAlN/VN superlattice structured PVD coatings: A new alternative in machining of aluminium alloys for aerospace and automotive components. Surf. Coat. Technol. 2006, 201, 265-272. [CrossRef]

24. Arumugam, P.U.; Malshe, A.P.; Batzer, S.A. Dry machining of aluminum-silicon alloy using polished CVD diamond-coated cutting tools inserts. Surf. Coat. Technol. 2006, 200, 3399-3403. [CrossRef]

25. Nouari, M.; List, G.; Girot, F.; Géhin, D. Effect of machining parameters and coating on wear mechanisms in dry drilling of aluminium alloys. Int. J. Mach. Tools Manuf. 2005, 45, 1436-1442. [CrossRef]

26. Sánchez, J.M.; Rubio, E.; Álvarez, M.; Sebastián, M.A.; Marcos, M. Microstructural characterisation of material adhered over cutting tool in the dry machining of aerospace aluminium alloys. J. Mater. Process. Technol. 2005, 164, 911-918. [CrossRef]

27. Pu, Z.; Umbrello, D.; Dillon, O.W.; Lu, T.; Puleo, D.A.; Jawahir, I.S. Finite element modeling of microstructural changes in dry and cryogenic machining of AZ31B magnesium alloy. J. Manuf. Process. 2014, 16, 335-343. [CrossRef]

28. Denkena, B.; Lucas, A. Biocompatible magnesium alloys as absorbable implant materials-Adjusted surface and subsurface properties by machining processes. CIRP Ann. 2007, 56, 113-116. [CrossRef]

29. Gariboldi, E. Drilling a magnesium alloy using PVD coated twist drills. J. Mater. Process. Technol. 2003, 134, 287-295. [CrossRef]

30. Dinesh, S.; Senthilkumar, V.; Asokan, P.; Arulkirubakaran, D. Effect of cryogenic cooling on machinability and surface quality of bio-degradable ZK60 mg alloy. Mater. Des. 2015, 87, 1030-1036. [CrossRef]

31. Menezes, P.L.; Kailas, K.S.V. Influence of roughness parameters on coefficient of friction under lubricated conditions. Sadhana 2008, 33, 181-190. [CrossRef]

32. Pu, Z.; Outeiro, J.C.; Batista, A.C.; Dillon, O.W.; Puleo, D.A.; Jawahir, I.S. Enhanced surface integrity of AZ31B mg alloy by cryogenic machining towards improved functional performance of machined components. Int. J. Mach. Tools Manuf. 2012, 56, 17-27. [CrossRef]

33. Shokrani, A.; Dhokia, V.; Newman, S.T. Environmentally conscious machining of difficult-to-machine materials with regard to cutting fluids. Int. J. Mach. Tools Manuf. 2012, 57, 83-101. [CrossRef]

34. Shaharun, M.A.; Ahmad, R.Y. Effects of irregular tool geometry and machining process parameters on the wavelength performance of process damping in machining titanium alloy at low cutting speed. Int. J. Adv. Manuf. Technol. 2016, 85, 1019-1033. [CrossRef]

35. Rubio, E.M.; Sáenz de Pipaón, J.M.; Villeta, M.; Sebastián, M.A. Experimental study for improving repair operations of pieces of magnesium UNS M11311 obtained by dry turning. In Proceedings of the 12th CIRP Conference on Modelling of Machining, San Sebastian, Spain, 7-8 May 2009; pp. 819-826.

36. Villeta, M.; Agustina, B.; Sáenz de Pipaón, J.M.; Rubio, E.M. Efficient optimisation of machining processes based on technical specifications for surface roughness: Application to magnesium pieces in the aerospace industry. Int. J. Adv. Manuf. Technol. 2011, 60, 1237-1246. [CrossRef]

37. Villeta, M.; Rubio, E.M.; Sáenz de Pipaón, J.M.; Sebastián, M.A. Surface finish optimization of magnesium pieces obtained by dry turning based on Taguchi techniques and statistical tests. Mater. Manuf. Process. 2011, 26, 1503-1510. [CrossRef]

38. Rubio, E.M.; Valencia, J.L.; Saá, A.J.; Carou, D. Experimental study of the dry facing of magnesium pieces based on the surface roughness. Int. J. Precis. Eng. Manuf. 2013, 14, 995-1001. [CrossRef]

39. Rubio, E.M.; Villeta, M.; Carou, D.; Saá, A.J. Comparative analysis of sustainable cooling systems in intermittent turning of magnesium pieces. Int. J. Precis. Eng. Manuf. 2014, 15, 929-940. [CrossRef]

40. Rubio, E.M.; Valencia, J.L.; Agustina, B.; Saá, A.J. Tool selection based on surface roughness in dry facing repair operations of magnesium pieces. Int. J. Mater. Prod. Technol. 2014, 48, 116-134. [CrossRef]

41. Carou, D.; Rubio, E.M.; Davim, J.P. Discontinuous cutting: Failure mechanisms, tool materials and temperature study-A review. Rev. Adv. Mater. Sci. 2014, 38, 110-124. 
42. Carou, D.; Rubio, E.M.; Lauro, C.H.; Davim, J.P. Experimental investigation on surface finish during intermittent turning of UNS M11917 magnesium alloy under dry and near dry machining conditions. Measurement 2014, 56, 136-154. [CrossRef]

43. Bureau of Labor Statistics, Productivity and Costs by Industry: Manufacturing and Mining Industries-2017, Economic New Release, 2018. Available online: www.bls.gov/news.release/pdf/prin.pdf (accessed on 3 July 2018).

44. Rubio, E.M.; de Agustina, B.; Marín, M.M.; Bericua, A. Cooling systems based on cold compressed air: A review of the applications in machining processes. Proc. Eng. 2015, 132, 413-418. [CrossRef]

45. Carou, D.; Rubio, E.M.; Davim, J.P. A note on the use of the minimum quantity lubrication (MQL) system in turning. Ind. Lubr. Tribol. 2015, 67, 256-261. [CrossRef]

46. Carou, D.; Rubio, E.M.; Davim, J.P. Analysis of ignition risk in intermittent turning of UNS M11917 magnesium alloy at low cutting speeds based on the chip morphology. Proc. Inst. Mech. Eng. Part B J. Eng. Manuf. 2015, 229, 365-371. [CrossRef]

47. Carou, D.; Rubio, E.M.; Lauro, C.H.; Davim, J.P. Experimental investigation on finish intermittent turning of UNS M11917 magnesium alloy under dry machining. Int. J. Adv. Manuf. Technol. 2015, 75, 1417-1429. [CrossRef]

48. Carou, D.; Rubio, E.M.; Lauro, C.H.; Davim, J.P. The effect of minimum quantity lubrication in the intermittent turning of magnesium based on vibration signals. Measurement 2016, 94, 338-343. [CrossRef]

49. Carou, D.; Rubio, E.M.; Agustina, B.; Marín, M.M. Experimental study for effective and sustainable repair and maintenance of bars made of Ti-6Al-4V alloy application to the aeronautic industry. J. Clean. Prod. 2017, 164, 465-475. [CrossRef]

50. Ben Artzy, A.; Munitz, A.; Kohn, G.; Bronfin, B.; Shtechman, A. Joining of light hybrid constructions made of magnesium and aluminum alloys. TMS Ann. Meet. 2002, 1, 295-302.

51. Ashby, M.F.; Brécht, Y.J.M. Designing hybrid materials. Acta Mater. 2003, 51, 5801-5821. [CrossRef]

52. Amancio, S. Innovative Solid-State Spot Joining Methods for Fiber Composites and Metal-Polymer Hybrid Structures; Joining in Car Body; Helmholtz-ZentrumGeesthacht: Geesthacht, Germany, 2012; pp. 1-47.

53. Gururaja, M.N.; Rao, A.N.H. A review on recent applications and future prospectus of hybrid composites. Int. J. Soft Comput. Eng. 2012, 1, 352-355.

54. Suryawanshi, B.K.; Prajitsen, G.D. Review of design of hybrid aluminum/composite drive shaft for automobile. Int. J. Innov. Technol. Explor. Eng. 2013, 2, 259-266.

55. Lee, D.; Morillo, C.; Oller, S.; Bugeda, G.; Oñate, E. Robust design optimization of advance hybrid (fiber-metal) composite structures. Compos. Struct. 2013, 99, 181-192. [CrossRef]

56. Rubio, E.M.; Villeta, M.; Valencia, J.L.; Sáenz de Pipaón, J.M. Experimental study for improving repair of magnesium-aluminium hybrid parts by turning processes. Metals 2018, 8, 59. [CrossRef]

57. Rubio, E.M.; Sáenz de Pipaón, J.M.; Valencia, J.L.; Villeta, M. Design, Manufacturing and Machining Trials of Magnesium Based Hybrid Parts, Machining of Light Alloys: Aluminium, Titanium and Magnesium; CRC-Press: Boca Raton, FL, USA, 2018; in press.

58. Zakaria, B.; Yazid, H. Friction stir welding of disimilar materials Aluminum Al6061-T6 to ultra low carbon steel. Metals 2017, 7, 42.

59. Casalino, G. Advances in welding metal alloys, Disimilar metals and additively manufactured parts. Metals 2017, 7, 32. [CrossRef]

60. Casalino, G.; Guglielmi, P.; Lorusso, V.D.; Mortello, M.; Peyre, P.; Sorgente, D. Lasser offset welding of AZ31B magnesium alloy to 316 stainless steel. J. Mater. Process. Technol. 2017, 242, 49-59. [CrossRef]

61. Li, Y.; Liu, C.; Yu, H.; Zhao, F.; Wu, Z. Numerical simulation of Ti/Al bimetal composite fabricated by explosive welding. Metals 2017, 7, 407. [CrossRef]

62. Wagner, F.; Zerner, I.; Kreimeyer, M.; Seefeld, T.; Sepold, G. Characterization and properties of dissimilar metal combinations of $\mathrm{Fe} / \mathrm{Al}$ and $\mathrm{Ti} / \mathrm{Al}$ sheet materials. In Proceedings of the ICALEO'01, Orlando, FL, USA, 15-18 October 2001.

63. Luo, J.G.; Acoff, V.L. Interfacial reactions of titanium and aluminum during diffusion welding. Weld. J. 2000, 79, 239-243.

64. Sáenz de Pipaón, M.J. Diseño y Fabricación de Probetas de Componentes Híbridos con Aleaciones de Magnesio para Ensayos de Mecanizado. Ph.D. Thesis, UNED (Universidad Nacional de Educación a Distancia), Madrid, Spain, 2013. 
65. Qi, X.; Song, G. Interfacial structure of the joints between magnesium alloy and mild steel with nickel as interlayer laser-TIG welding. Mater. Des. 2010, 31, 605-609. [CrossRef]

66. Nasiri, A.M.; Li, L.; Kim, S.H.; Zhou, Y.; Weckman, D.C.; Nguyen, T.C. Microstructure and properties of laser brazed magnesium to coated steel. Weld. J. 2011, 90, 211-219.

67. Nasiri, A.M.; Weckman, D.C.; Zhou, Y. Interfacial microstructure of diode laser brazed AZ31B magnesium to steel sheet using a nickel interlayer. Weld. J. 2013, 92, 1S-10S.

68. Dau, J.; Lauter, C.; Damerow, U.; Homberg, W.; Tröster, T. Multi-material systems for tailored automotive structural components. In Proceedings of the 18th International Conference on Composite Materials, Jeju Island, Korea, 21-26 August 2011.

69. Frantz, M.; Lauter, C.; Tröster, T. Advanced manufacturing technologies for automotive structures in multi-material design consisting of high-strength steels and CFRP. In Proceedings of the 56th International Scientific Colloquium, Ilmenau, Germany, 12-16 September 2011.

70. DRL. Innovation Report 2011; Institute of Composites Structures and Adaptative Systems: Braunschweig, Germany, 2011.

71. Amin, N. Titanium Alloys-Towards Achieving Enhanced Properties for Diversified Applications. Edited by A.K.M. Nurul Amin, 2012. Available online: www.intechopen.com (accessed on 1 July 2018).

72. Bisker, J.; Christman, T.; Allison, T.; Goranson, H.; Landmesser, J.; Minister, A.; Plonski, R. DOE Handbook, Primer on Spontaneous Heating and Pyrophoricity; U.S. Department of Energy: Washington, DC, USA, 1994; pp. 1-68.

73. NanoMAG. Hydro Magnesium's Machining Magnesium; Technical Document; NanoMAG: Livonia, MI, USA, 2009; Available online: http:/ / nanomag.us (accessed on 22 November 2017).

74. Layens, C.; Peters, M. Titanium and Titanium Alloys. Fundamentals and Applications; Wiley-VCH Verlag GmbH \& Co.: Weinheim, Germany, 2003.

75. Sáenz de Pipaón, J.M.; Rubio, E.M.; Villeta, M.; Sebastián, M.A. Analysis of the chips obtained by dry turning of UNS M11311 magnesium. In Proceedings of the 3rd Manufacturing Engineering Society International Conference 2009, Alcoy, Spain, 17-19 June 2009; pp. 33-38.

76. Sáenz de Pipaón, J.M.; Rubio, E.M.; Villeta, M.; Sebastián, M.A. Selection of the cutting tools and conditions for the low speed turning of bars of magnesium UNS M11311 based on the surface roughness. In Innovative Production Machines and Systems; Whittles Publishing: Scotland, UK, 2010; pp. 174-179, ISBN 978-184995-006-0.

77. El-CGizawy, A.S.; Khasawneh, F.A.; Bogis, H. Drilling process design for hybrid structures of polymer composites over titanium alloy. J. Mater. Sci. Eng. 2016, 5, 243. [CrossRef]

78. Matsumara, T.; Tamura, S. Cutting simulation of titanium alloy drilling with energy analysis and FEM. In Proceedings of the 15th CIRP Conference on Modelling of Machining Operations, Karlsruhe, Germany, 11-12 June 2015; pp. 252-257.

79. Poutord, A.; Rossi, F.; Paulachon, G.; M'Saoubi, R.; Abrivard, G. Local approach of wear in drilling Ti6Al4V/CFRP for stack modelling. In Proceedings of the 14th CIRP Conference on Modelling of Machining Operations, Turin, Italy, 13-14 June 2013; pp. 316-321.

80. Shetty, P.K.; Shetty, R.; Shetty, D.; Rehaman, F. Machinability study on dry drilling of titanium alloy Ti-6Al-4V using L9 othogonal array. Procedia Mater. Sci. 2014, 5, 2605-2614. [CrossRef]

81. Ramulu, M.; Spaulding, M. Drilling of hybrid titanium composite laminate (HTCL) with electrical discharge machining. Materials 2016, 9, 746. [CrossRef] [PubMed]

82. Grasin, K.; Ayvar-Soberanis, S. Evaluation of workpiece temperature during drilling of GLARE fiber metal laminates using infrared techniques: Effect of cutting parameters, fiber orientation and spray mist application. Materials 2016, 9, 622. [CrossRef]

83. Abdulgadir, M.; Demir, B.; Emre Turam, M. Hybrid reinforced magnesium matrix composites (Mg/Sic/GNPs): Drilling investigation. Metals 2018, 8, 215. [CrossRef]

84. Li, M.; Huang, M.; Jiang, X. Study on burr occurrence and surface integrity during slot milling of multidirectional and plain woven CFRPs. Int. J. Adv. Manuf. Technol. 2018, 97, 163-173. [CrossRef]

85. Bellini, C.; Polini, W.; Sorrentino, L. A new class of thin composite parts for small batch productions. Adv. Compos. Lett. 2014, 23, 115-120.

86. Liao, B.B.; Liu, P.F. Finite element analysis of dynamic progressive failure properties of GLARE hybrid laminates under low-velocity impact. J. Compos. Mater. 2018, 52, 1317-1330. [CrossRef] 
87. Montgomery, D.C. Design and Analysis of Experiments; John Wiley \& Sons, Inc.: Hoboken, NJ, USA, 2017.

88. ISO. Geometrical Product Specifications (GPS) Surface Texture: Profile Method. Rules and Procedures for the Assessment of Surface Texture; International Organization for Standardization: Geneva, Switzerland, 1998.

89. Zhang, P.F.; Churi, N.J.; Treadwell, C. Mechanical drilling processes for titanium alloys: A literature review. Mach. Sci. Technol. 2008, 12, 417-444. [CrossRef]

90. Celik, Y.M. Investigating the effects of cutting parameters on the hole quality in drilling the Ti-6Al-4V alloy. Mater. Technol. 2014, 48, 653-659.

91. Rahim, E.A.; Sharif, S.; Sasahara, H. Machinability of titanium alloys in drilling. Chapter 6. In Titanium Alloys-Towards Achieving Enhanced Properties for Diversified Applications; Edited by A.K.M. Nurul Amin; 2012; Available online: www.intechopen.com (accessed on 1 July 2018).

92. Chong, K.Z.; Shih, T.S. Optimizing drilling conditions for AZ61A magnesium alloy. Mater. Trans. 2002, 43, 2148-2156. [CrossRef]

93. Taguchi, G. System of Experimental Design: Engineering Methods to Optimize Quality and Mimimize Costs, 1st ed.; Kraus International Publications: New York, NY, USA, 1987; Volume 1.

94. The American Society of Mechanical Engineers. Surface Texture: Surface Roughness, Waviness and Lay; ANSI/ASME B46.1-2009; ASME: New York, NY, USA, 2010.

(c) 2018 by the authors. Licensee MDPI, Basel, Switzerland. This article is an open access article distributed under the terms and conditions of the Creative Commons Attribution (CC BY) license (http://creativecommons.org/licenses/by/4.0/). 